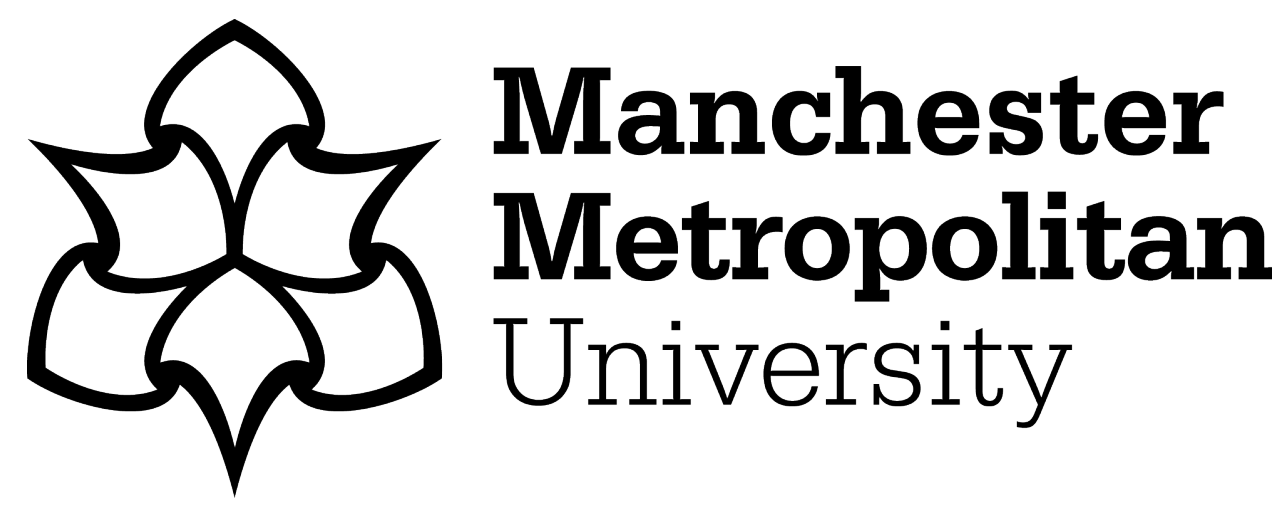

Rousell, DS and Cutter-Mackenzie, Amy (2019) Uncommon worlds: toward an ecological aesthetics of childhood in the Anthropocene. In: Research Handbook on Childhoodnature: Assemblages of Childhood and Nature Research. Springer International Handbooks of Education. Springer. ISBN 9783319519494

Downloaded from: https://e-space.mmu.ac.uk/620894/

Version: Accepted Version

Publisher: Springer

Please cite the published version 


\title{
Uncommon Worlds: Towards an ecological aesthetics of childhood in the Anthropocene
}

David Rousell, Manchester Metropolitan University, UK

Amy Cutter-Mackenzie, Southern Cross University, Australia

\begin{abstract}
In addressing the need for a more robust engagement with aesthetics in posthumanist studies of childhood and nature, this chapter makes some tentative steps towards an ecological aesthetics of childhood that is responsive to Whitehead's speculative philosophy. In doing so, the chapter takes an alternative theoretical approach from much of the 'common worlds' scholarship that has emerged in recent years, while making the case for a new aesthetics of childhood that is responsive to the accelerating social, technological, and environmental changes of the Anthropocene epoch. Our approach foregrounds the singularity of children's aesthetic experiences as relational-qualitative 'intensities' that alter the fabric of nature as an extensive continuum held in common. We therefore argue that every moment in the life of a child is an uncommon and unrepeatable occasion through which the common world of nature is felt, perceived, and experienced differently. This eco-aesthetic approach is developed further through the analysis of photographs taken by children as part of the Climate Change and Me project, which has mapped children and young people's affective responses to climate change over a period of three years in New South Wales, Australia. Rather than working with images as representations or analogic signifiers for children's experience, we analyse how each photograph co-implicates children's bodies and environments through affective vectors of feeling, or 'prehensions'. This leads us to reframe aesthetic notions of image, sensibility, perception, and causality in relational terms, while also acknowledging the individuation of childhood experiences as 'creaturely becomings' that produce new potentials for environmental thought and behaviour.
\end{abstract}

Keywords: speculative philosophy; Whitehead; ecological aesthetics; posthumanism; Anthropocene; climate change education

\section{Introduction}

We must think of Nature without any residual anthropocentrism: that is to say, without exempting ourselves from it, and also without remaking it in or own image. (Shaviro, 2015, p. 216)

In addressing the need for a more robust engagement with aesthetics in posthumanist studies of childhood and nature, this chapter aims to make some tentative steps towards an ecological aesthetics of childhood that is grounded in Whitehead's (1978) speculative philosophy. By integrating Whitehead's philosophy with posthumanist approaches to the life sciences (Frost, 2016) and media studies (Hansen, 2015), we work to establish the contours of an ecological aesthetics that is both attuned and responsive to the rapidly changing material conditions of contemporary life. In doing so, the chapter takes an alternative theoretical approach from much of the 'common worlds' scholarship that has emerged in recent studies of childhood and nature (see, for instance, Malone 2015; Rautio, 2014; Taylor, 2013; Taylor \& Pacini-Ketchabaw, 2015).

In the first part of the chapter, we begin by making the case for a new aesthetics of childhood that is responsive to the accelerating social, technological, and environmental changes of the Anthropocene 
epoch. We consider the recent turn towards 'common worlds pedagogies' in environmental education and childhood studies, while also highlighting the need for a more intensive and affirmative engagement with non-anthropocentric and non-representational aesthetic theories within these fields. Taking Whitehead's aesthetic order of nature as our starting point, we begin to develop an ecological aesthetics that is orientated towards the 'uncommon' dimensions of children's experience in and of the Anthropocene epoch. This allows us to foreground the singularity of children's aesthetic experiences as relational-qualitative 'intensities' that alter the fabric of nature as an extensive, vibratory continuum held in common. In doing so, we actively work to reframe aesthetic notions of image, sensibility, perception, and causality in relational terms, while also acknowledging the individuation of childhood experiences as 'creaturely becomings' that produce new potentials for environmental thought and behaviour.

In the second part of the chapter, we develop this eco-aesthetic approach to childhoodnature scholarship further by analysing a series of photographs taken by children as part of the Climate Change and Me project. This project has mapped children and young people's affective responses to climate change over a period of three years in Northern New South Wales, Australia. Elsewhere we have analysed the political and ethical implications of children's embodied participation in the project (Cutter-Mackenzie \& Rousell, in press), the emergence of speculative fiction as research method (Rousell, Cutter-Mackenzie, \& Foster, 2017), as well as the project's methodological innovations and insights (Cutter-Mackenzie \& Rousell, this volume). Here we focus specifically on the speculative analysis of photographic images created by children over the course of the project. Drawing on Whitehead's (1978) theory of prehension in conversation with biocultural insights from the life sciences (Frost, 2016) and media studies (Hansen, 2015), we analyse the sensuous, causal, and virtual elements of children's photographs as occasions of felt relation and environmental encounter. Rather than working with images as representations or analogic signifiers for children's experience, we explore how each photograph co-implicates children's bodies and environments through affective vectors of feeling, or what Whitehead (1978) calls 'prehensions'. This leads us to propose an ecological aesthetics of childhood that affirms both the 'common world' of nature as an extensive continuum, along with the 'uncommon worlds' through which children make aesthetic contact with other creatures, environments, and modes of existence. The chapter concludes by considering the pedagogical implications of children's photographic practices, focusing on Whitehead's (1967) concept of the 'art of life' as a guiding proposition for aesthetic cultivation and bodily engagement.

\section{A New Aesthetics of Childhood}

Recently there has been a turn towards more relational, collective, and distributed conceptions of children and childhood in the social sciences (Lee, 2013), the environmental humanities (Taylor, 2013), and environmental education (Malone, 2015). In many cases this turn has emerged in response to posthumanist concerns regarding the onset of the Anthropocene epoch, a time in which the very nature of childhood is being transformed by anthropogenic climate change, species extinction, resource contamination, ubiquitous computation, and biotechnological mechanisms of social control (Lee \& Motzkau, 2012). Scholars working the intersections between the fields of childhood studies and environmental education have proposed that the onset of the Anthropocene calls for new conceptualisations of children and childhood (Malone, 2016; Somerville, 2017; Taylor 2017), along with new research methodologies and techniques that are attuned to the complex dynamics of children's social and ecological worlds (Cutter-Mackenzie \& Rousell, 2014). As the relentless acceleration of social, technological, and environmental change continues to erode the humanist foundations of dualistic Western thought, we are now witnessing a proliferation of biosocial (Lee, 
2013; Youdell, 2017), posthumanist (Hultman \& Lenz-Taguchi, 2010; Malone, 2017 ; Rautio, 2013), Indigenous (Cajete, 2010), socioecological (Cutter-Mackenzie et al, 2014) and post-developmental (Blaise, 2014) framings of childhood. While these approaches tend to share a commitment to reconceptualising childhood within more than human environments, assemblages, societies, and worlds, they have tended to focus predominantly on the ethical, political, and pedagogical implications of such radically inclusive ecologies of childhood. As such, the aesthetic, imaginative, and experiential qualities of children's environmental sensibilities have often been backgrounded by 'ontological' shifts from individuals to collectives, binaries to hybrids, and constructivisms to materialisms. In many cases, this has involved a reinvigoration of the concept of the political collective or 'commons' as an assemblage of human and nonhuman constituents that compose the messy and entangled worlds of children and childhood (Taylor, 2013). This backgrounding of aesthetics has been particularly evident in the recent flurry of scholarship under the rubric of 'common worlds pedagogies', many of which have drawn extensively on the work of Latour (2004) and Haraway (2008) to account for the common worlds that children inhabit with myriad other agencies and forms of life (Taylor 2017; Taylor \& Pacini-Ketchabaw, 2015).

While we acknowledge the rigour and timely significance of the work currently being undertaken to reinvigorate a more than human commons, in this chapter we argue that such turns call for a new aesthetics of childhood as much as they require a new politics and ethics of relationality. It has been widely acknowledged that environmental education has not adequately engaged with the aesthetic dimensions of experience (Ingram, 2012; Inwood \& Taylor, 2012; Stables, 2003), while an internet search at the time of writing revealed no substantive treatment of aesthetics within published literature associated with 'common worlds pedagogies' and related research. The reasons for this eschewal of aesthetics is not entirely clear. One possible reason could be the distancing of posthumanist studies of childhood from Enlightenment and Romantic aesthetic traditions which have perpetuated purist, progressive, and sublime images of childhood and nature as idealised forms (Taylor, 2013, p. 13). We concur that such a distancing is both timely and necessary, as the humanising influences of Romantic idealism are often the default philosophical touchstones for contemporary environmentalist movements (Morton, 2007), as well as the 'child in nature' movements associated with forest schools and related environmental education initiatives (Malone, 2016). In resisting the dominant tropes of such humanistic ideals in environmental education and childhood studies, critical posthumanist studies have shown how representations of the 'natural child' have been used to perpetuate political regimes of anthropocentrism and human exceptionalism, effectively legitimising the very social and environmental injustices which they seek to avoid (Malone, 2015; Taylor, 2013). The dominant cultural logic of Kantian aesthetics has also used ideal qualities (such as beauty) and capacities (such as art, language, and technology) as criteria for placing humans above other creatures, consequently positioning the external environment or 'nature' as an objective correlate or backdrop for human progress, cognition and knowledge (Morton, 2013; Shaviro, 2014).

As Morton's (2007) meticulous deconstruction of the lingering dominance of Romanticism has shown, the dismantling of such idealist aesthetic regimes has been a core project of the arts for over two centuries. While Kantian aesthetics continues to exert a stultifying influence on studies of childhood, education, and environment (Prout, 2005; Taylor, 2013), in the art world these idealisms have long since been replaced by the austerities of social realism, the machinic abstractions of modernism, the anti-humanist deconstructions of postmodernism, and the relational assemblages and spatiotemporal mobilities of much contemporary art (Groys, 2008). Equivalently, contemporary work in art theory, cultural studies, and media studies have been largely influenced by Deleuzian, Whiteheadian, and new materialist aesthetics of immanence, sensation, relationality, affectivity, animality, and becoming (see, for instance, Hansen, 2015; Massumi, 2011; Shaviro, 2009). As Kennedy (2000, p. 30) 
notes, the materialist turn in aesthetics means that beauty is no longer 'consilient with goodness, the romantic, or transcendent notions, but to a feeling of duration, movement, and continual process'. Rather than a disavowal of outmoded idealist aesthetics, posthumanist childhood studies could benefit from a more affirmative engagement with the relational and materialist turns in aesthetics in art, media, design, architecture, technology, and film studies over the last three decades. Haraway's (2016) recent work could provide a catalyst in this regard, as she advocates the development of a 'new new synthesis' between the environmental arts, humanities and sciences which would tie 'together human and nonhuman ecologies, evolution, development, history, affects, performances, technologies, and more' (p. 63).

Haraway's new synthesis of life sciences, environmental humanities, and relational arts shows the potential for a transdisciplinary ecological aesthetics to transform studies of childhood in ways that are responsive to the Anthropocene's most pressing challenges. By drawing on the vigorous development of posthumanist aesthetic theories in such diverse enterprises as philosophy, art, cultural studies, and the biological sciences, a new aesthetics of childhood becomes both possible and necessary in reconfiguring our understandings of children's learning experiences and environments. This is not to argue that posthumanist studies of childhood/nature need to become more aestheticised or artistic (though this may also be the case), but rather that the aesthetic dimension of such work is inseparable from the political and ethical issues that appear to necessitate an 'ontological' reappraisal of childhood in relation to nature. We therefore argue that the posthumanist and postanthropocentric turns towards relationality, collectivity, biosociality, affect, process, emergence, becoming, entanglement, and 'common worlds' need to be understood as aesthetic movements, prior to their instantiation as movements in ethics, politics, or pedagogical practice. What these posthumanist turns both instantiate and require, we suggest, is an ecological aesthetics that reconfigures how children's bodies, environments, spaces, places, times and relations are composed, felt, sensed, and experienced. Such a new aesthetics could be located in the creatureliness of children's felt relations and bodily capacities, while remaining attuned to incipient ethical and political ecologies as they emerge with/in environments that simultaneously surround, permeate, sustain, constrain, and animate children's everyday lives (Frost, 2016).

\section{The Creatures That Become}

In developing an alternative approach to posthumanist studies of childhood in this chapter, we negotiate a (re)turn to Alfred North Whitehead's speculative philosophy as an ecological aesthetics of becoming and felt relationality. Whitehead's philosophy has undergone a renewal in recent posthumanist scholarship, as the relational system of thought he developed nearly a century ago offers a visionary alternative to dualistic and anthropocentric philosophies that have dominated Western philosophy for millennia (Shaviro, 2014; Stengers, 2011). In Whitehead's (1978) speculative philosophy, every actual occasion of experience is understood as a 'creature of becoming' that sustains its own existence through affective encounters with other creatures. 'The actual occasions are the creatures which become,' Whitehead (p. 35) writes, 'and they constitute a continuously extensive world'. In other words, everything that exists is a creature because all actual entities are, more or less, capable of experience. All things are creatures of experience. The differences between entities are therefore considered aesthetic differences of degrees, qualities, speeds, manners, and intensities of experience, rather than ontological differences in kind. A stone, for instance, may have a relatively dense, slow, and contracted quality of experience compared to the experience of a child. A child will likely have a more intense experience than the stone, with greater degrees and capacities for sensitivity, contrast and transformation over a shorter duration. This means that the difference between the experience of a stone and the experience of a child is aesthetic, rather than ontological 
(Robinson, 2009). In other words, creaturely experiences are distinguished by differences in becoming (as the aesthetic mode or manner of existence) rather than differences in being (as the ontological essence or substance of existence).

For Whitehead, this differential quality of experience as becoming extends from the cosmological to the quantum, making his philosophy a form of 'pan-experientialism' compatible with process thinkers such as Bergson and Deleuze. As Robinson (2009, p. 22) writes, each of these three thinkers foregrounds 'the implicit aesthetic genesis, order and creative organisation of experience, with experience here understood as enlarged and not simply equivalent to human experience'. We also note the compatibility of Whitehead's philosophy of organism with recent insights from the life sciences, which have revealed the extent to which genetic, cellular, and bodily activities are dynamically modulated by both immediate and transgenerational changes in social and ecological conditions (Frost, 2016). As Protevi (2013) argues, contemporary advances in the biological, computational, and cognitive sciences provide empirical support for the process philosophies of Whitehead, Bergson, Simondon, and Deleuze, while also demanding a posthumanist aesthetics that acknowledges the environmental porosity, plasticity, and permeability of sensing organisms and the environments they co-inhabit with other creatures (see also Alaimo, 2010). We therefore take the lead from Frost (2016) in conceiving of children as 'biocultural creatures' and the environments they populate as 'biocultural habitats', to the extent that the term "biocultural" 'encapsulates the mutual constitution of body and environment, of biology and habitat' (p. 4). Within this assemblage of biocultural creatures and habitats as the mutually conditioning elements of life, the element of 'culture' is understood as a process of cultivation which provides a medium and milieu through which bodies and environments emerge, grow, develop, interact, and eventually perish.

We can now return to the example of the stone and the child in order to better understand what Whitehead means by the 'creatures that become'. The child picks up the stone on the river bank, feeling its weight in the hand, the pock-marked texture of its surface, the way it catches the light as she turns it over. Both child and stone are creatures: they are accretions of all the relations they have experienced since they came into existence, including the auto-affective experiences of their own bodies, spaces, and times. They are distinct creaturely entities, each with their own 'routes of inheritance' (Whitehead, 1978), and yet they inhabit, if only for a moment, a shared 'biocultural habitat' (Frost, 2016). And in this imagined moment of encounter, as the child handles the stone and then skims it across the surface of the water, an event occurs that is not of the child or the stone but of the aesthetic relation between child and stone. This felt relation between creatures of becoming is what Whitehead refers to as 'prehension'. Prehension is the way that creatures sense, perceive, and incorporate the experiences of other creatures through the aesthetic feeling and intensity of relation. This also means that creatures become what they are by prehending other creatures, including themselves (Shaviro, 2009). We can attempt to encapsulate this in a rather simple formulation: creatures are what they feel.

\section{Common and Uncommon Worlds}

In order to make sense of Whitehead's 'common world' pan-experientialism, we need to expand our understanding of aesthetic experience to encompass what he refers to as the 'aesthetic order' (1926, p. 91). Indeed, we find within Whitehead's radically non-anthropocentric philosophy a system in which all orders of existence (including the biological, the social, the conceptual, the epistemic, the semiotic, the political, the ethical, the spiritual, the actual, and the virtual) are circumscribed within the aesthetic order of nature. As Jones (1998, p. 20) notes, this conception of aesthetic order is coextensive with the weight of causal complexity as it emerges through natural processes and accretes over time. For Whitehead (1967b, p. 53), the aesthetic order refers to a common world of nature as it 
is collectively experienced with each passing moment, along with all of the historical data, virtual potentialities and entangled sensibilities that each creature inherits from previous events. 'The actual elements perceived by our senses are in themselves the elements of a common world,' Whitehead (1967a, p. 88) writes. Every creature that exists is always already immersed 'within a world of colours, sounds, and other sense-objects, related in space and time to enduring objects such as stones, trees, and human bodies. We seem to be ourselves elements of this world in the same sense as are the other things which we perceive' (p. 89).

The ways that creatures become sensible elements of each other's worlds is crucial to understanding the distinction between common and uncommon worlds that we wish to unfold in this chapter. Whitehead's formulation of a common world is the vibratory continuum of nature that extends from sub-atomic to cosmological proportions and time-scales. This common world is extensive, continuous, and objective to the extent that it includes every creature and occasion of experience that actually exists. This world is common because it includes all possible elements, actualities, and potentialities of experience. And yet these elements, actualities, and potentialities of experience are also changing, with every moment, in ways that are not reducible to anything common. These are what Whitehead calls the 'actual worlds' of the creatures who become, what we might call the biocultural habitats and intensive milieus of creatures and the societies they populate (Frost, 2016). While these uncommon worlds are not isolated from one another, we would not consider them 'common' because they are always being felt differently by the particular creatures who actually experience them. Hence every creature (from a child, to a stick insect, to a mushroom, to an asteroid) feels its actual world differently. This gives every creature its own relational intensity as an individual, with its own uncommon world that is determined by how creatures prehend their interpenetrating worlds in different ways. Indeed, this privacy of subjective experience is what makes the assemblage of a heterogeneous society, ecology, or collective of creatures possible.

Based on this differentiation between common and uncommon worlds, we can tease out some initial propositions for reconceptualising children and childhood. Firstly, as biocultural creatures, children never experience the same actual world twice because each experience constitutes a novel synthesis of relations from a series of disjunctive elements (molecules, bodies, societies, places, times, materials, concepts, feelings, perceptions, discourses). This fits with Taylor's (2013) assertion, drawn from her work with Arrente peoples of Central Australia, that 'children are their worlds. It is the particularities and distinctive features of these worlds that makes children who they are'. However, we suggest that the very distinctiveness of children's actual worlds is indicative of their uncommonality as individual creatures with their own private intensities of feeling and bodily capacities for aesthetic experience. Every moment in the life of a child is an uncommon and unrepeatable instance through which the common world of nature is felt, perceived, and experienced differently.

Second, and as Whitehead (1978, p. 35) makes clear, the common world of nature is not continuous in itself (or causa sui), but rather becomes continuous through the ongoing proliferation of uncommon worlds in all their teeming intensities and entanglements of creaturely relations. In other words, the common world of nature relies on uncommon occasions of experience to continue its extension. This means that a child's process of becoming (or what Haraway calls 'worlding') is fundamentally creative: the child feels the actual world in a way that is qualitatively different from any other occasion, and in doing so, adds her experience to the extensive continuum of nature. In this way, the extensive continuum of nature both produces and is produced by the intensive qualities of experience that constitute children as 'creatures that become'. Put another way, everything that a child experiences 
contributes to the continuity of nature, while at the same time irrevocably changing what nature can be.

\section{The Whir of Worldly Sensibility}

In a common world in which everything both senses and is sensed through differential qualities of aesthetic experience, what comes to matter is the distribution and processing of aesthetic sensibility within more than human political ecologies and collectives. Whitehead describes how 'we find ourselves in a buzzing world, amid a democracy of fellow creatures' $(1978, p$. 50). This buzzing world of creaturely activity 'expresses the relation of causal interaction between entities and their actual worlds' (Jones, 1998, p. 20). As we described in the section above, the causal interactions between creatures and their habitats constitute the aesthetic order of nature as an extensive, vibratory continuum, or common world. The idea that the very consistency, order, and causal infrastructure of nature is altered and redistributed by the aesthetic experiences of creatures (such as children) offers a basis for a new ecological aesthetics of childhood. It means that children literally reconfigure the virtual structures of nature through intensive processes of individuation, creating new potentials for life through the dynamic relations between 'a milieu of interiority and a milieu of exteriority' (Simondon, 1995, p. 223). Whitehead (1978) describes this process of individuation as 'constructive functioning', whereby the trafficking between intensive and extensive milieus, between bodies and environments, involves a creative synthesis of differential elements that produces the singular (uncommon) world of a living organism or creature (see also Protevi, 2013; Deleuze, 1994).

In taking this proposition a step further, we suggest that the molecular, metabolic, semiotic, perceptual, conceptual, and technological trafficking between children's bodies and their biocultural habitats is a function of what Hansen $(2015$, p. 3) calls 'the distribution of worldly sensibility'. For Hansen, worldly sensibility refers to the causal infrastructure of the vibratory continuum that operates above, around, and below the thresholds of human sense perception and consciousness (p. 2). The cells of our bodies, for instance, are constantly responding to the surrounding environment in ways that we are only vaguely aware of at the conscious level, if at all. These processes operate through what Whitehead $(1978 ; 1929)$ calls the mode of 'causal efficacy', which he contrasts with the perceptual mode of 'presentational immediacy'. Where the mode of presentational immediacy involves the sensuous perception of vivid values as experienced through qualia such as colours, sounds, textures, tastes, and smells, causal efficacy is a function of the underlying causal infrastructure of nature as a vibratory continuum (Hansen, 2015). Presentational immediacy gives us access to the sensuous qualities of our external environments to reveal clearly recognisable objects of perception, but it lacks temporal duration, thickness, and subtlety. In this sense, presentational immediacy is only the province of sufficiently complex creatures, such as humans and other animals, who are capable of experiencing 'the clear and distinct representation of sensations in the mind of a conscious, perceiving subject' (Shaviro, 2014, p. 23). Although Whitehead (1927, p. 23) describes such perception as 'vivid, precise, and barren', it is through this representational mode of perception that 'the world discloses itself to be a community of actual things, which are actual in the same sense as we are' (p. 21).

Causal efficacy, on the other hand, refers to the 'vague (nonrepresentational) way that entities affect and are affected by one another through a process of vector transmission' (Shaviro, 2014, p. 23). It is thus more accurately described as a mode of sensibility than a mode of perception (Hansen, 2015). Causal efficacy opens the range and distribution of sensibility to the entire aesthetic order of nature, and places all things that exist on the same ontological footing. For human creatures, causal efficacy means that even our most clear and distinct perceptions are mediated through complex causal processes that lie above, below, or beyond our consciousness, including those processes associated with our own bodily capacities. 'We see the picture, and we see it with our eyes; we touch the wood, 
and we touch it with our hands; we smell the rose, and we smell it with our nose; we hear the bell, and we hear it with our ears; we taste the sugar, and we taste it with our palate' (Whitehead, 1927, p. 50). In these examples, causal efficacy is associated with what Whitehead $(1978, p .81)$ calls 'the withness of the body', a position which implicates the body and its capacities within the elemental distribution of worldly sensibility across the whole of nature. In the mode of causal efficacy, 'the inflow into ourselves of feelings from enveloping nature overwhelm us ... the presentations of sense fade away, and we are left with the vague feeling of influences from vague things around us' (Whitehead, 1978 , p. 176). As Hansen (2015, p. 49, italics in original) explains, the vague, haunting sensations of causal efficacy are indexed to 'the material causal linkages that exist and have force outside of the realm of impressions, ideas, and ideas of impressions - outside the domain of sense perception proper'. Underneath the incessant whirring of cicadas on a summer afternoon is the imperceptible whir of worldly sensibility, a whole buzzing world of nature seething just below the threshold of conscious, sensory perception.

In bringing the vibratory continuum of nature into contact with the perceptual impressions and affective intensities of individual creatures, Whitehead's theory of prehension effectively fuses aesthetic experience with the material causal infrastructure of nature's spatiotemporal dynamisms (see also Protevi, 2013). As Manning and Massumi (2014) further note, both presentational immediacy and causal efficacy are present to varying degrees in human experience, and it becomes a matter of how these modes of perception and sensibility achieve various fusions, syntheses, and vicarious interchanges. In the following sections, we focus more specifically on how children's photographs can embody these kinds of bioaesthetic fusions and syntheses, which bring together the subjective experiences of children with the vibratory continuum of worldly sensibility.

\section{Pieces of the Earth}

Over the last three years, the Climate Change and Me project has mapped children and young people's affective, creative and theoretical responses to climate change through participatory ethnography and socially-engaged arts practices. This has involved working with 135 children and young people (aged 9-14) from across Northern NSW, Australia as co-researchers who were directly involved in all phases of the research. The artworks, essays, videos, photographs, poems and fictional works created through this research were assembled into a public touring exhibition called Past Now Future, which was viewed by over 8,000 members of the public over an eight-week period. This material also provided the resources for a transdisciplinary climate change curriculum, which is currently being implemented in regional primary and secondary schools across Northern NSW (see www.climatechangeandme.com.au). Over the course of the project, photography emerged as a creative research method that opened up spaces for children and young people to think and act differently in relation to climate change. This process was set in motion through the project's emergent research design and child-framed methodology, which allowed us to work collaboratively with children and young people within a "co-research playspace" (Cutter-Mackenzie \& Rousell, 2014; see also Cutter-Mackenzie \& Rousell, this volume). Initially this involved hosting research training workshops in local schools, where students were introduced to the concept of the Anthropocene epoch and learned to conduct ethnographic interviews and observation, take field notes, and use creative practices such as drawing, photography, and video as educational research methods. We also developed a customised and secure social media interface that enabled the young researchers to post and comment on each other's photographs, as well as initiate their own small projects, discussions and games within a blogspace we called the "CC + Me Hangout". 


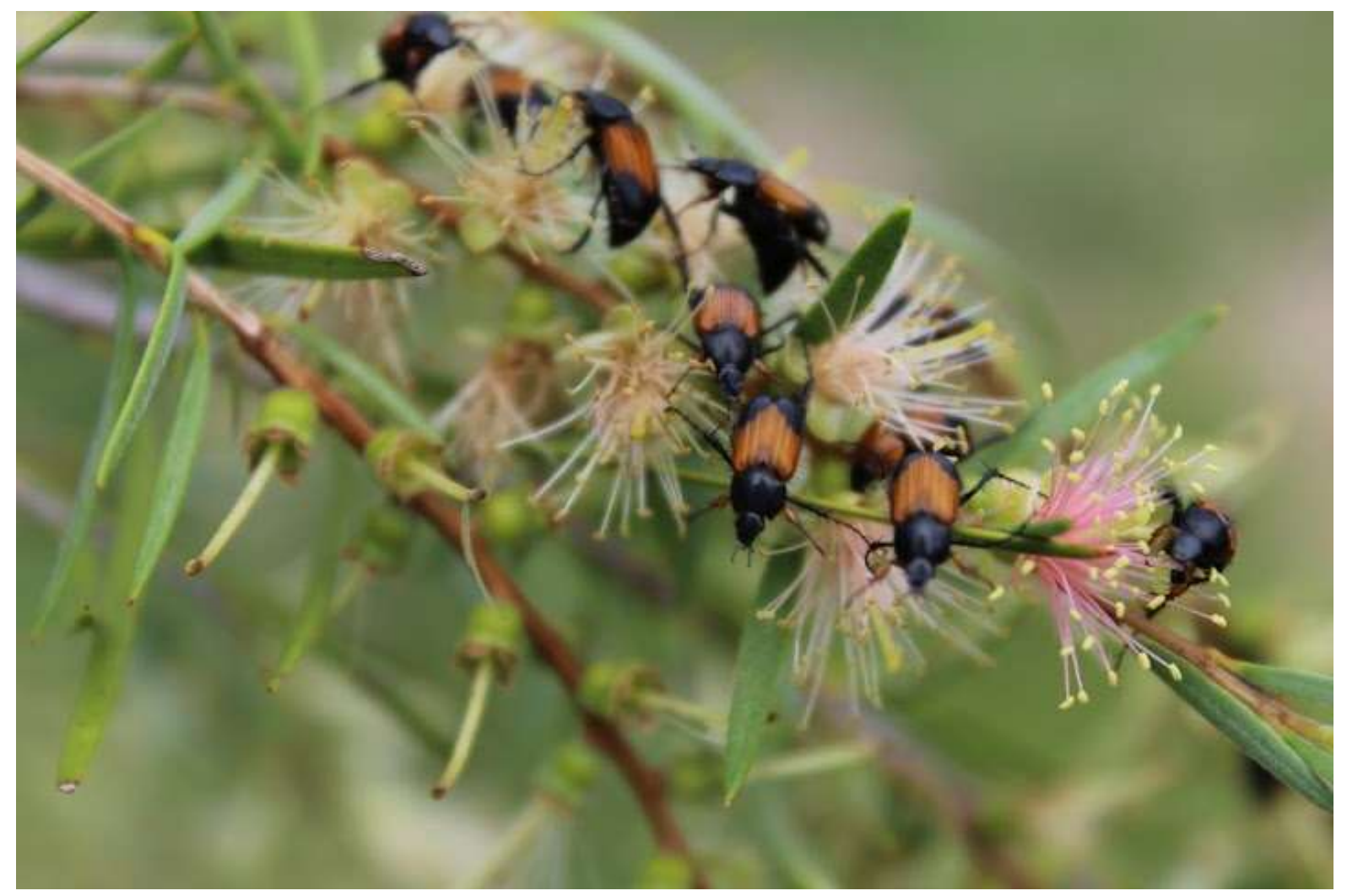

Figure 1: A photograph submitted by Grace (age 11) with the subtitle 'The little worlds that exist around us'

We found that many of the co-researchers tended to gravitate towards the medium of photography, as we witnessed an inundation of over 4,000 images uploaded to the project website in the first year of the project alone. As we progressed through the analytic stages of the project, we hosted a series of creative ThinkTank workshops where the children worked through the data en masse. This included a process of collectively curating the photographs down to a series of 200 images that the children felt expressed their experiences of climate change, and of life in the Anthropocene more broadly. The children also wrote messages on the backs of the photographs at this time, with a combined function of interpreting the affective qualities of the images while also translating those feelings for a public audience. At this point we worked closely with the children to design and assemble a collaborative artwork for the touring exhibition which involved transferring the photographs onto plywood tiles coated in beeswax. This process effectively archived the images in an encaustic wax medium that would preserve them for millennia, while also transforming the image from a reproducible digital file into a unique work of art. As shown in Figure 1, the wax transfer process altered the colour, texture, and form of the image to achieve a ghostly rendering encased in the surface of the wax. These rematerialisations of the children's photographs were then fitted with magnetic strips, allowing them to be mounted on the surface of a whiteboard and iteratively re-arranged in the manner of a fluid montage. This work was entitled 'Pieces of the Earth', and formed one of three major works in the Past Now Future exhibition, along with a series of video installations and a book of the children's poetry, photographs, critical essays, and speculative fiction (see Rousell \& Cutter-Mackenzie (ed.), Handbook Companion). 


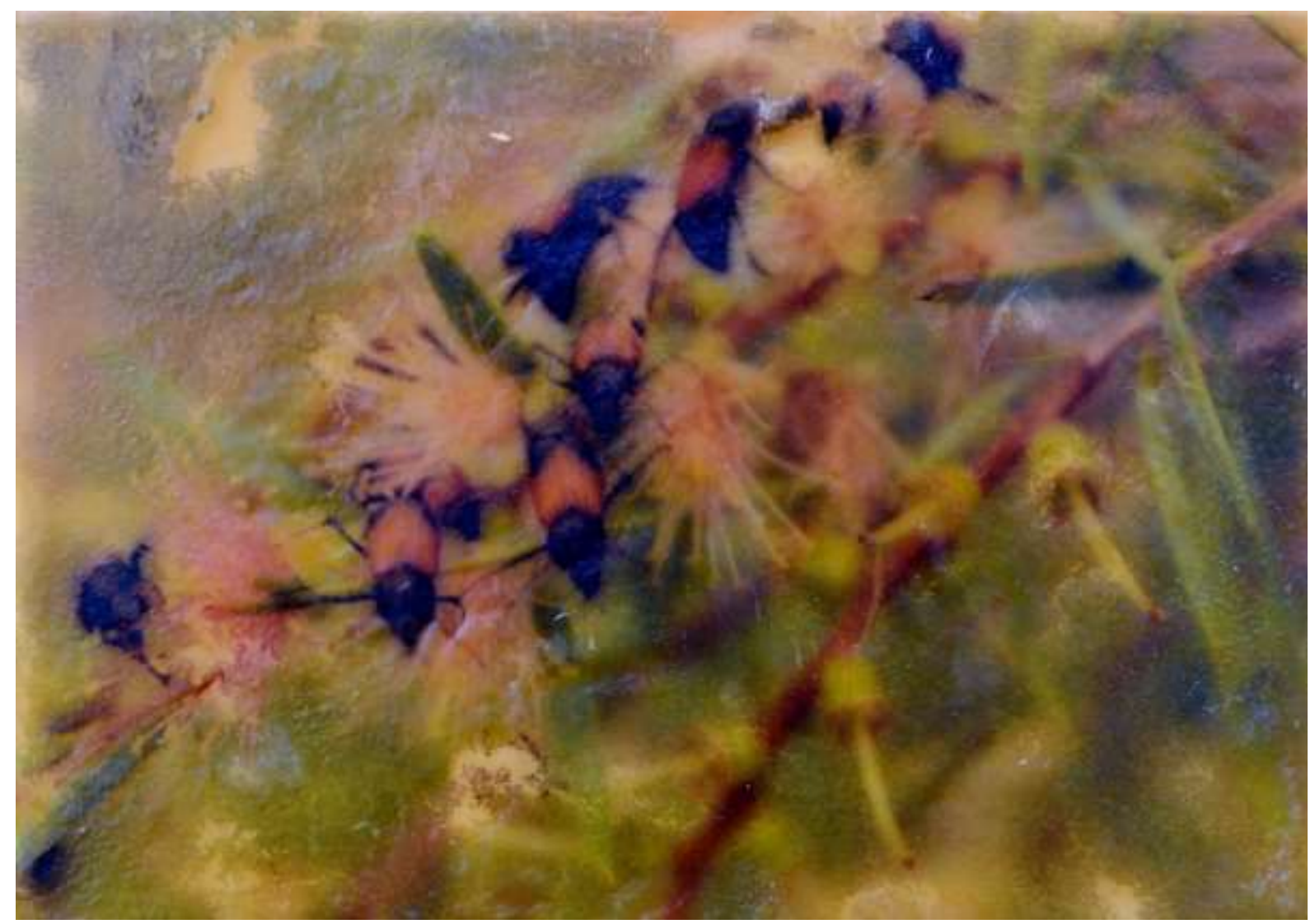

Figure 2: Grace's wax transfer of the 'little worlds' image using encaustic medium on plywood

\section{Theorising the Image as Surface}

In this section we analyse how different images were materialised in the Climate Change and Me project through children's aesthetic engagements with their changing environments. Rather than interpreting the images as representations of what children think or know about climate change, we follow the intensive transformations of images as immersive surfaces within which children are implicated as biocultural creatures. We understand the surface of the image to be a composition of creaturely prehensions, or what Whitehead calls 'vectors of feeling', as well as an interface that opens onto the vibratory continuum of nature. Our intention is to plumb the immersive depths of the image's surface, moving away from linguistic and optical frames of reference to embrace a tactile materiality that fuses the immediacy of aesthetic feeling with the vague penumbra of worldly sensibility. Through our focus on images as sites of aesthetic contact and felt relationality, our research essentially comes to involve 'the production of surfaces, their multiplication and their consolidation' (Deleuze, 1990, p. 125). In this way, we see the surface of the image as a nexus between the uncommon worlds of children as biocultural creatures and the vibratory continuum of nature as a common world of material causality, relationality, sensibility, and extension.

Our analysis begins with a series of digital photographs taken by children, which we understand as prehensions of children's actual worlds as they exist(ed) in the places and times of the photographs. The first photograph was taken by an 11 year-old girl named Grace, who walked alone in the wet sclerophyll forest near her grandmother's house in a remote area of Northern NSW (Figure 3). Moistened by a heavy rain that had fallen over previous weeks, the forest was teeming with fresh explosions of fungi, vegetation, and insect life as Grace collected a series of highly detailed and saturated images. The second photograph was taken by 12 year-old Kairo, who made her way to a remote coastal location in Northern NSW just before dawn (Figure 4). Her images capture the Pacific 
Ocean's horizon in the liminal moments between night and day, such that the surfaces of water and sky become washed with colour values too subtle and blended to name.

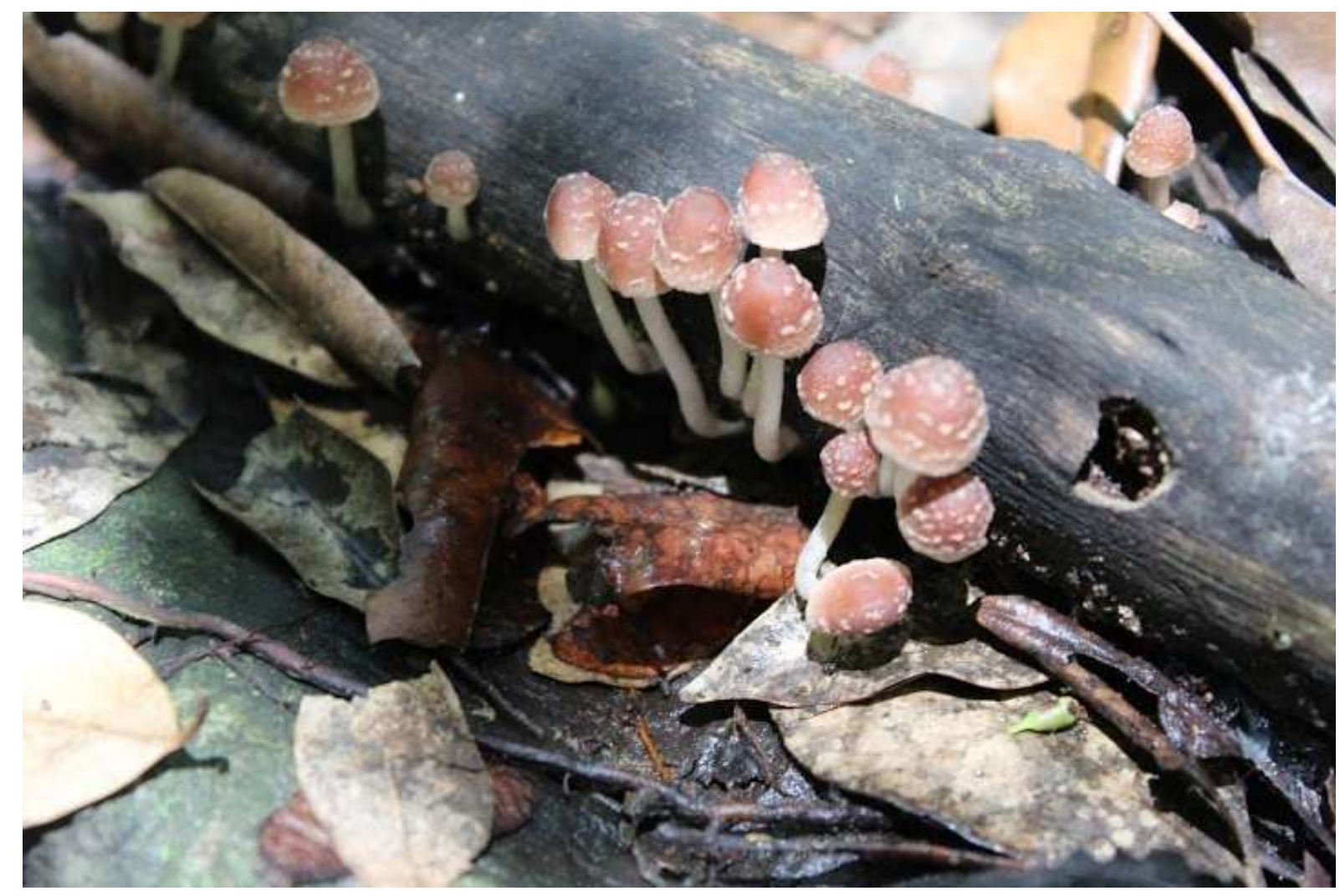

Figure 3: Photograph taken by Grace (age 11) during a morning walk in wet sclerophyll forest

Each of these images emits a certain dark brilliance, a gradient of contrasts that results in a particular intensity of aesthetic feeling emanating from the surface of the photograph. In this first analytic pass over the images, we are aware of values of colour, light, shadow, and texture resolving into recognisable forms on the surfaces of the photographs. The presentational immediacy of atmospheric qualities within a distributed environmental field resolve into clearly delineated spatial relationships: mushrooms growing on a branch, an ocean reflecting the sky. As Massumi and Manning (2014) note, there is a certain aesthetic enjoyment or 'entertainment' that accompanies presentational immediacy prior to the resolution of the field's surface effects into forms and spatial relations. Entertaining the immediacy of the image also brings our attention to the contemporaneous nature of events that occur relationally, and yet independently, within the field of experience (Whitehead, 1927). There are interpenetrating values, such as colour and moisture, which are shared between the ocean and the sky in Figure 4, a resonance between surfaces. This is to entertain the surface effects of the relational field itself as an elemental environment, a mode of perception closer to the experiences of autistic people or of hallucinogenic states than to neurotypical consciousness.

Yet even before the surface resolves into recognisable forms and affordances (a mushroom you could pick, an ocean you could hear, smell, and dive into), our awareness of the image has been influenced by a more vague mode of sensibility associated with causal efficacy. The mode of causal efficacy reveals that there is much more occurring in these images, both perceptually and causally, than what can be seen within the frame of the photograph. In the first image we can barely sense Grace's damp foray into the rainforest, and share in her increasing wonder as she photographs the wild variety of fungal constellations appearing at her feet. In the second image we catch a vague, penumbral sense 
of Kairo knee-deep in the waters of Angel Beach at dawn, trying to steady the camera as she darkly contemplates rising sea levels and human failures. In each of these images we see what the child sees, and what the lens of her camera sees, at a particular moment in time and space that occurred two years ago at the time of writing. Attending to causal efficacy gives us a haunting sense of what lies beyond the perceptible objects within the frame of the image, the weight of multiple spaces and times that condition the image directly, aesthetically, materially, causally.

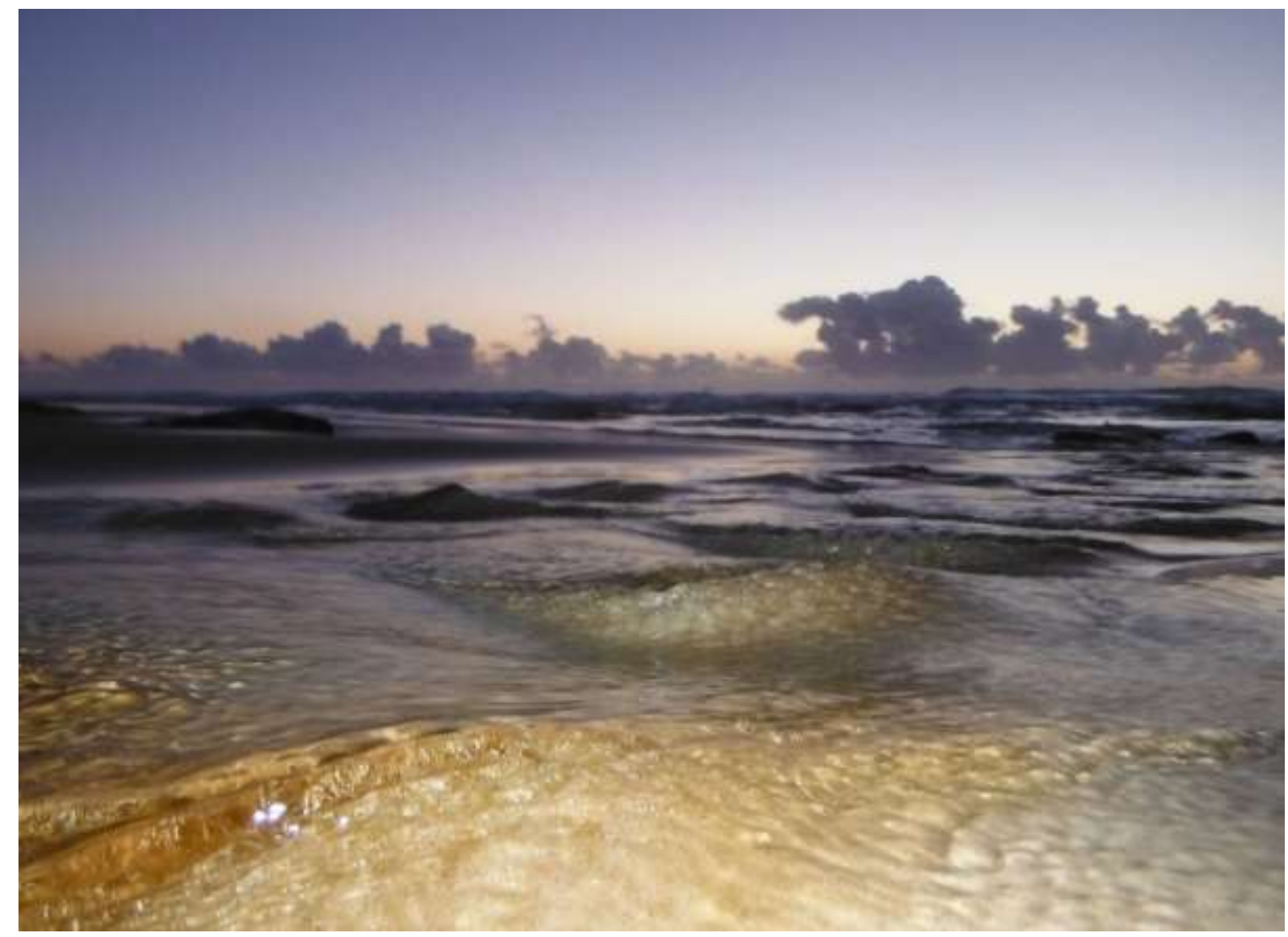

Figure 4: Photograph taken by Kairo (age 12) just before dawn at Angel Beach, NSW

The sensing body of the camera is crucial in this mediated configuration of child and environment, as it captures and renders the sensory data of the occasion in ways that no human can do. As Hansen $(2015$, p. 24) argues, such media technologies are able to 'capture a wealth of data from worldly sensibility- including data about our own implication in it- and feed this data forward into a future or just-to-come moment of conscious perception'. In other words, digital cameras give us access to nature itself in ways that conscious, human perception does not. We understand the extrahuman sensing capacity of the camera as a function of what Whitehead (1978) calls the 'vector-character' of prehension. The camera renders the image as a conduit or channel for vectors of feeling that extend from one unique perspective on the universe to another: sunlight falling on the forest floor, the roiling ocean at dawn, the wind-swept eyes of a child, the ink-saturated pages of a book. All of these and more are events within an ecology of sensation that proliferates through an intricate meshwork of aesthetic prehensions. This sensory ecology is what makes it possible for you to the encounter these images and words as you flip the pages of this Handbook. In this way, each image expresses a capacity to 'channel the force of worldly sensibility' as the 'pure potentiality' of the vibratory continuum of nature as the 'total environment' (Hansen, 2015, p. 238). In prehending the image, we also grasp a vague sense of the whole of nature seething in the depths of its surface. 
Through this speculative analysis of the image as a conduit for vectors of feeling and worldly sensibility, we find that it is no longer the human/nonhuman distinction that really matters, or maybe even that this distinction is no longer possible. The images themselves show nothing human, and yet the body of the child is felt as a living creature, invisible and yet implicated in the surface of the image. The sensible appearance of the image and the material conditions of its appearance are inseparable, such that the surface enables sensing bodies to make aesthetic contact with one another at a distance (Shaviro, 2014, p. 148). This fusion of presentational immediacy with causal efficacy opens the image beyond any representational or discursive function. What we are dealing with instead are the differential relations between the forces of aesthetic appearance and material causality, between the resolution of perceptual elements within a sensory ecology and the material conditions through which that whole sensory ecology operates. Child-environment prehensions contract the elemental qualities of worldly sensibility into an image, narrowing the field of potential experience to produce an intensity of contrast that is felt on the surface. This is what we mean when we say that the surface of the image has depth: it has depth of contrast, depth of feeling, depth of intensity, depth of sensibility, and depth of potential.

\section{Rematerialising the Image as Surface}

Having established the surface of the image as a site of aesthetic contact between sensing bodies and environments, we now consider the transductive potentials of the image through its capacities for material transformation. As described in the preceding section, the children selected 200 images for the exhibition which they transferred onto tablets covered with an encaustic medium (beeswax and damar resin). The digital images were printed out in high-resolution using a laser printer, and then pressed into a molten layer of encaustic medium on the surface of the tablets.

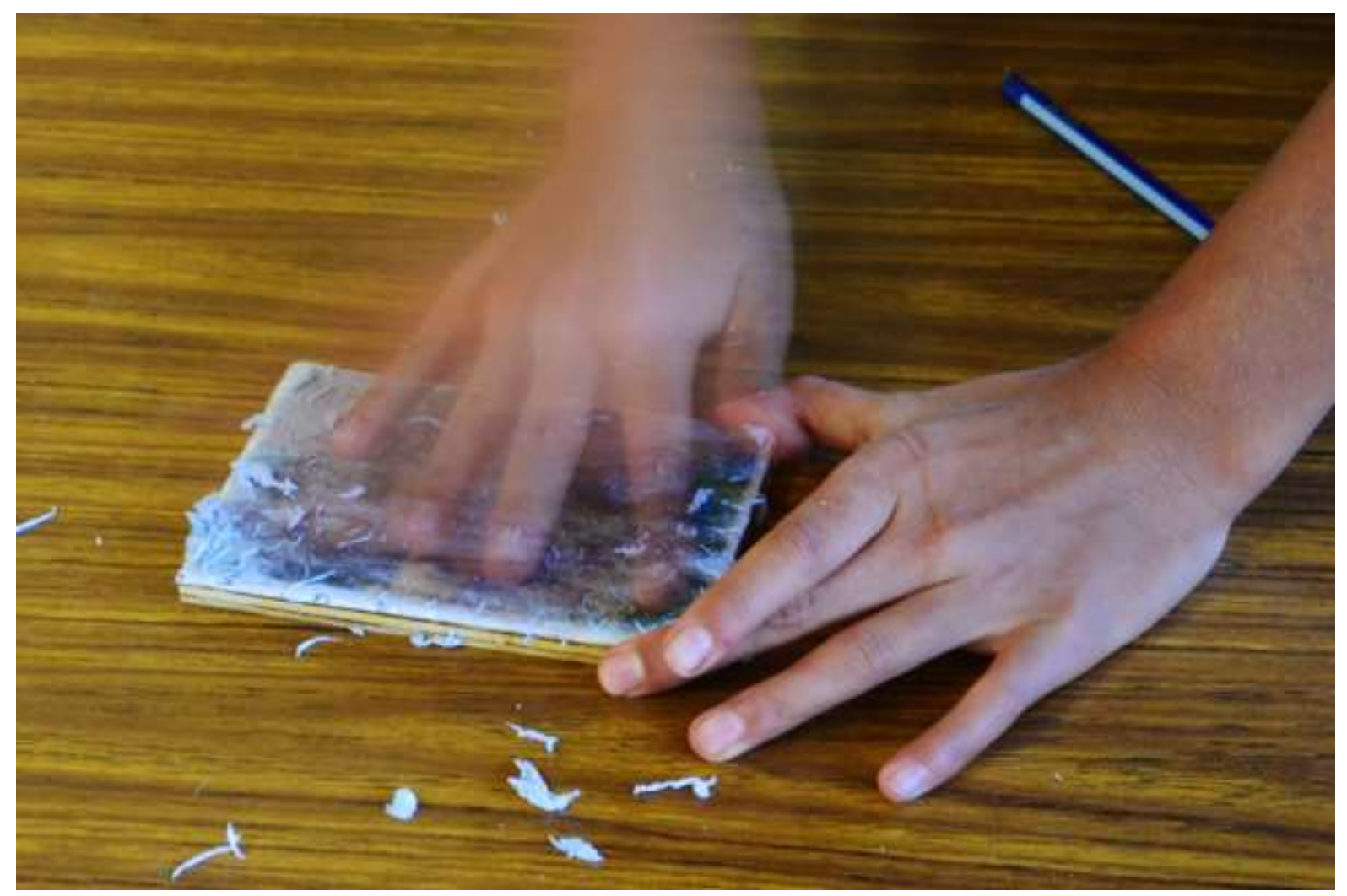

Figure 5: Rubbing the paper off the surface of the wax transfer once the ink has been embedded 
After applying extensive pressure to the image with the back of a spoon, the paper from the original print could be removed by repeated rubbing with fingers (see Figure 5). The tablet was then carefully reheated to a molten state in order to lift the underlying medium to the rippling surface, thus fixing the image within a translucent layer of wax and resin. What appears on the surface of the tablet is a ghostly monoprint of the digital image, as the printing ink is suspended within an archival medium that can, under certain conditions, preserve the image for thousands of years (see Figure 6).

The wax transfer process demonstrates how the image can function not as a representation of childhood but as a surface that channels vectors of childhood/nature sensibility through material transduction and transformation. The image is seen to slide from one medium into another, as the transfer process effectively resingularises a digital image through its deformation and reformation as an analogue image (see Guattari, 2008). In other words, the transfer process unleashes the virtual potentials of the image to become something else, something new, within a topological field of nearinfinite possibilities. 'Think of each image receding into its deformation, as into a vanishing point of its own twisted versioning,' Massumi (2002, p. 133) writes. Paradoxically, we see the image become more singular by differentiating, by resingularising back on itself as 'matter in analogue mode' (p. 135). The wax transfer is a process of transduction from one medium to another, from a medium of digital code to a medium of analogue materials and bodily sensations. The precarious virtuality of the image is brought to the fore, as its remateralisation in analogue form is scarred by the process of deformation, or sensible qualities that were lost in the process of transfer. 'A feeling bears on itself the scars of its birth', Whitehead (1978, p. 226-227) writes. 'It retains the impress of what it might have been, but is not'.

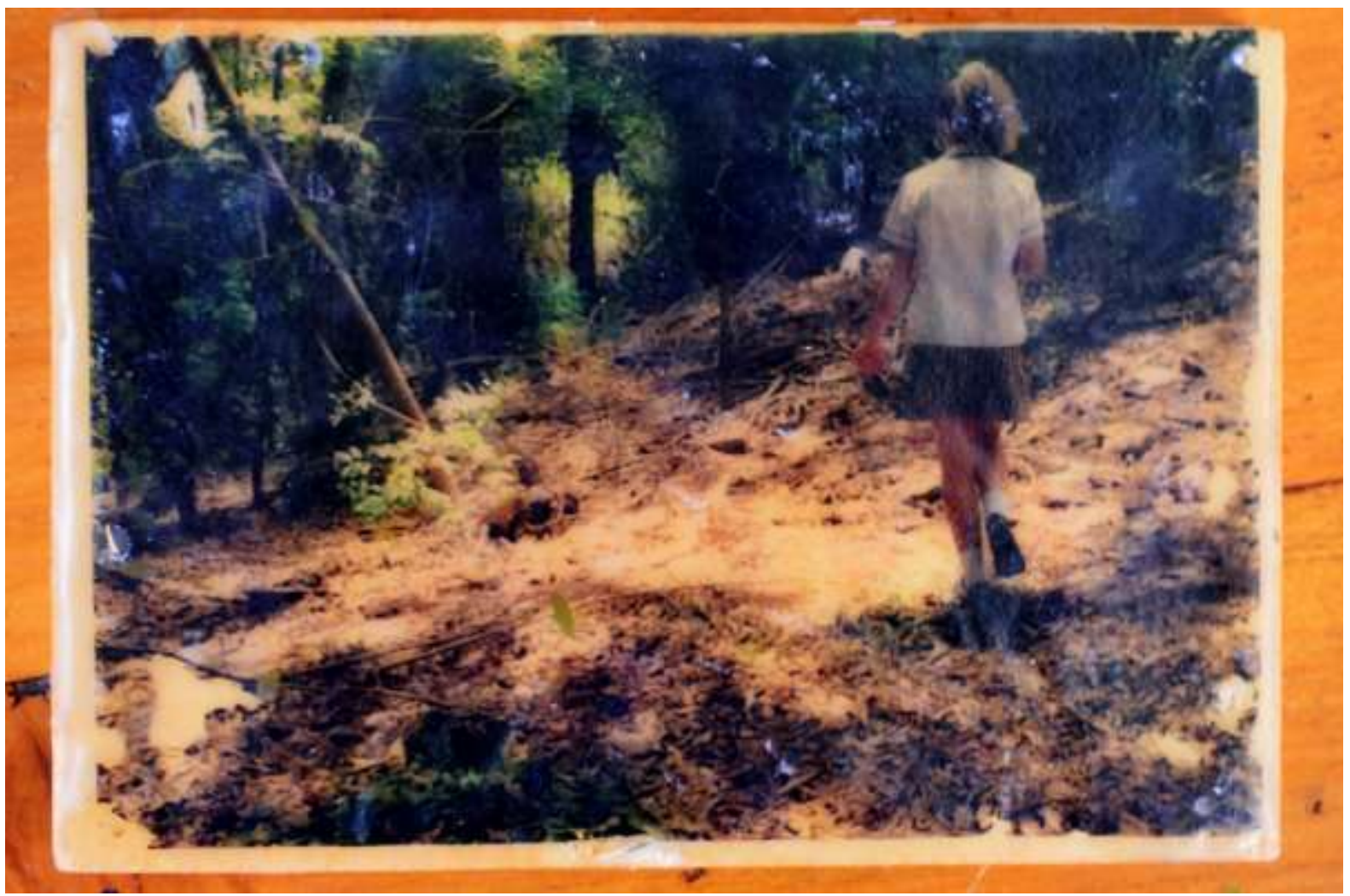

Figure 6: An example of a wax transfer image that creates a fusion of body and environment

In becoming analogue, the image implicates the body of the child more thoroughly into the depths of its surface. The fusion of bodies and environments that we discussed in the previous section becomes even more palpable, more intricately embedded and folded together through a renewed tactility of 
the child-environment nexus. Perhaps the digital code of the photograph was only a temporary holding pattern between the child's environmental experience and the rematerialisation of the analogue image on the wax tablet. As a medium for making aesthetic contact with children and their biocultural environments, the transfer process replaces the representational ocularity of vision with a tactility that crosses temporal and spatial divides. We can touch the child's sense of the forest on the surface of the wax tablet, revealing what Hansen (2006, pp. 70-71) calls an 'infratactility', or primordial tactility, operating at the very 'heart of the sensible'. The wax transfer process intensifies the tactility of the photograph, and in doing so, enables a more thorough melding of children and their environments on the surface of the image (see Figure 6). While there is a loss in clarity and resolution, there is a gain in analogue sensation and worldly sensibility. The images become more permeable, taking on the biocultural tactility of skin, flesh, and membrane, as they come to embody the 'sometimes fluid and sometimes disjunctive processes of responsive development, dissipation, intensification, and transformation' (Frost, 2016, p. 149). The images become, quite literally, Pieces of the Earth rendered from the biocultural interactions between children's bodies and their changing environments.

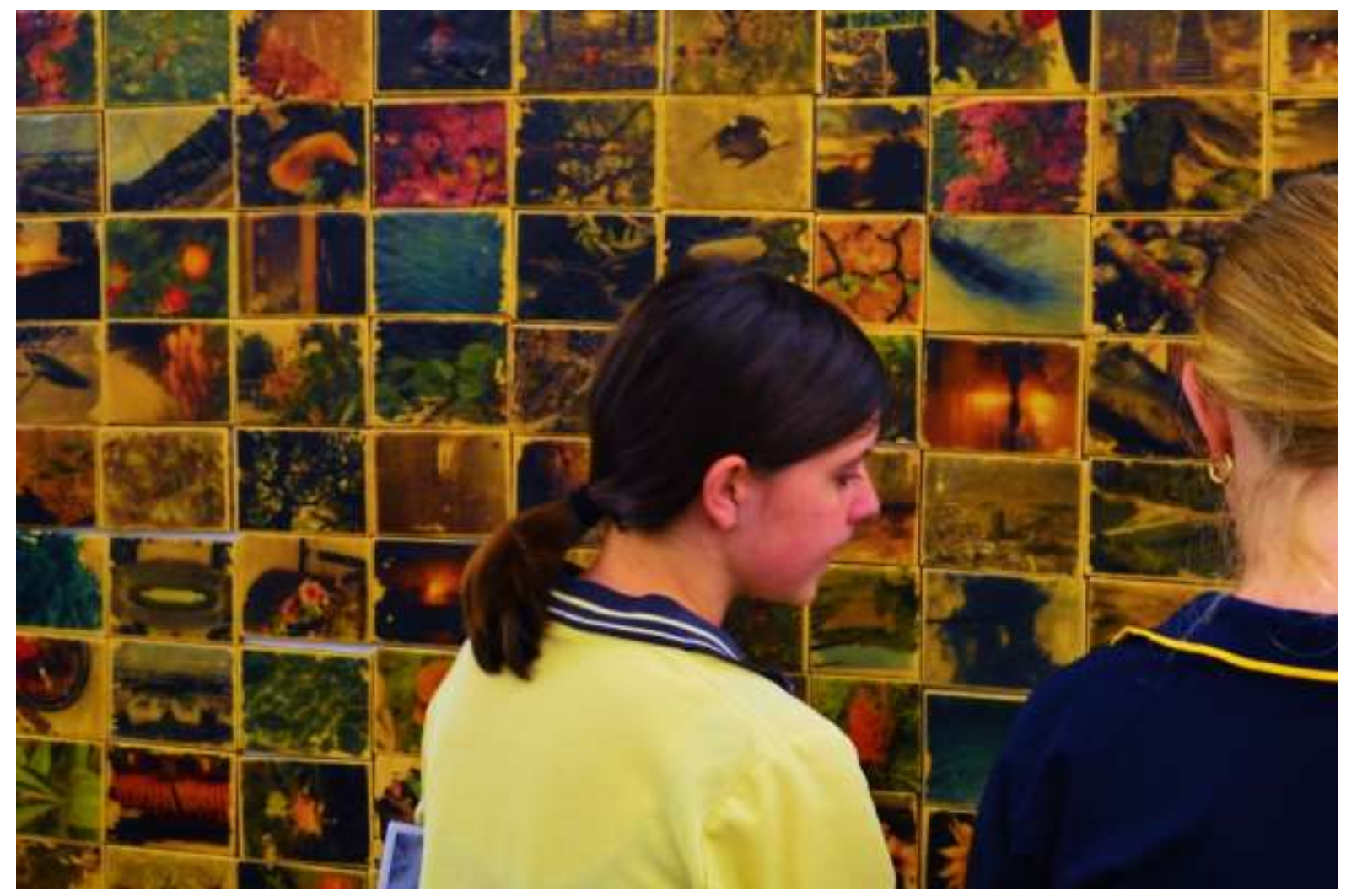

Figure 7: Children engaging with the collaborative artwork Pieces of the Earth as a fluid montage of surfaces

\section{Conclusion: Cultivating the Art of Life}

In this chapter we have taken some steps towards the development of an ecological aesthetics of childhood that is responsive to the challenges of the Anthropocene epoch. We began by outlining the need for a more robust engagement with aesthetics in posthumanist studies of childhood/nature as part of the broader call for a 'new synthesis' of the environmental arts, humanities, and sciences (Haraway, 2016). Drawing on Whitehead's speculative philosophy in conjunction with insights from the life sciences and media studies, we proposed a series of relationships between the common world of nature and the uncommon worlds of children as biocultural creatures. This led to a further series 
of distinctions between presentational immediacy and causal efficacy as modes of perception and worldly sensibility, with an emphasis on the fusion of children's perceptual experiences with the causal infrastructure of natural systems and dynamic spatiotemporal processes. We then extended this ecological-aesthetic framework through an analysis of children's environmental photographs as part of the Climate Change and Me project, including the analysis of digital photographs in relation to the analogue rematerialisation of images through a wax transfer process. Using aesthetic concepts of intensity, contrast, sensibility, and surface, our analysis focused on developing the image as a site for making aesthetic contact with the embodied relationships between children and their changing environments.

This brings us to the perennial question of whether, and how, an image becomes a work of art. Does the child's photograph become art when it is curated and exhibited as such? Does the transductive process of the wax transfer qualify the image as art through its material transformation? While we do not offer a definitive answer to these questions here, we suggest that the transfer process intensifies both the elemental and aesthetic qualities of the image, and in doing so, pushes the image to the threshold at which image becomes art. To the extent that the image becomes more singular through an artful process, and that this process introduces qualitative changes into biological, social, and material processes, then we would say that it becomes art. Hence, it is not so much the image itself that we advance as art but the transformative processes that are both attributed to and unleashed by the image through forces of material production and the intensities of affective encounters. It is in this sense that we associate art with artfulness, as an aesthetic way or manner in which life is lived and experienced within an ecology of sensation (Manning, 2016).

We also recognise artfulness as the way in which the aesthetic becomes pedagogical, inasmuch as a work of art is able to redistribute worldly sensibility at the levels of the social, the ecological, and the planetary. We therefore conclude with a pedagogical perspective, as we position artfulness as the cultivation of aesthetic sensibilities and capacities for practicing what Whitehead (1929) calls 'the art of life'. We see the art of life as a pedagogy for cultivating environmental awareness through the aesthetic selection and recomposition of sensory elements in relation to bodily movement and perception. 'For example,' Whitehead (1929, p. 200) writes, 'the mere disposing of the human body and the eyesight so as to get a good view of the sunset is a simple form of artistic selection. The habit of art is the habit of enjoying vivid values'. Whitehead positions the body as the pivot point for the art of life, an aesthetic practice of enjoying the sensible intensities, values, and contrasts that emerge in the relations between interior and exterior milieus. 'Each individual embodies an adventure of existence. The art of life is the guidance of this adventure' (Whitehead, 1967a, p. 39). The art of life is the art of the creature, the art of the organism, the art of attuning one's biocultural body to an ecology of sensation through aesthetic techniques of existence. These are techniques that meld the aesthetics of beauty with environmental sensation, such that the beautiful is no longer associated with taste or judgement, but with 'a felt "immediacy", "force", or "intensity" in process' (Kennedy, 2000, p. 31).

In this chapter we have proposed an ecological aesthetics of childhood drawing from speculative philosophies of nature, media, and the body. We have analysed the sensory practices of children as embodied techniques for cultivating environmental attunement through aesthetic experience. Grace walking in the forest finding mushrooms at her feet, or Kairo wading into the waters of Angel Beach to take photographs at dawn: these are moments in which creatures are guided by the art of life, such that body and environment become fused in the production of life itself as a work of art (Rousell \& Fell, in press). These are occasions of vivid experience never to be repeated; they are the uncommon worlds of children as biocultural creatures, each a unique perspective on the universe as it is felt differently and yet together, with each passing moment. 


\section{References}

Alaimo, S. (2010). Bodily natures: Science, environment, and the material self. Bloomington: Indiana University Press.

Blaise, M. (2014). Interfering with gendered development: A timely intervention. International Journal of Early Childhood, 46(3), 317-326.

Cutter-Mackenzie, A., \& Rousell, D. (in press). Education for What? Shaping the emerging field of climate change education with children and young people as co-researchers. Children's Geographies.

Cutter-Mackenzie, A., \& Rousell, D. (in press). The Mesh of Playing and Researching in the Reality of Climate Change: Children's Research Play Spaces. In International Research Handbook on ChildhoodNature. The Netherlands: Springer.

Deleuze, G. (1994). Difference and repetition (P. Patton, Trans.). New York, NY: Columbia University Press.

Eernstman, N., van Boeckal, J., Sacks, S., \& Myers, M. (2012). Inviting the unforeseen: A dialogue about art, learning and sustainability. In A. E. J Wals \& P.B. Corcoran (Eds.), Learning for Sustainability in Times of Accelerating Change (pp. 201-212). Wageningen, the Netherlands: Wageningen Academic Publishers.

Frost, S. (2016). Biocultural creatures: Toward a new theory of the human. Durham, NC: Duke University Press.

Groys, B. (2008). The topology of contemporary art. In T. Smith, O. Enwezor \& N. Condee (Eds.), Antinomies of art and culture: Modernity, postmodernity and contemporaneity (pp. 71-82). Durham, NC: Duke University Press.

Guattari, F. (2008). The three ecologies. London, UK: Continuum.

Hansen, M.B. (2006). Bodies in code: Interfaces with digital media. New York: Routledge.

Hansen, M.B. (2015). Feed-Forward: On the future of $21^{\text {st }}$ Century media. Chicago, IL: University of Chicago Press.

Haraway, D.J. (2008). When Species Meet. Minneapolis: University of Minnesota Press.

Haraway, D. J. (2016). Staying with the trouble: Making kin in the Cthulucene. Durham, NC: Duke University Press.

Inwood, H., \& Taylor, R. W. (2012). Creative approaches to environmental learning: Two perspectives on teaching environmental art education. International Electronic Journal of Environmental Education, 2(1), 66-76.

Jones, J. (1998). Intensity: Essay in Whiteheadian ontology. Nashville, TN: Vanderbilt University Press.

Kennedy, B. (2000). Deleuze and cinema: The aesthetics of sensation. Edinburgh, UK: Edinburgh University Press.

Latour, B. (2004). Politics of nature. Cambridge, MA: Harvard University Press. 
Lee, N. (2013). Childhood and biopolitics: Climate change, life processes and human futures. Rotterdam, NL: Springer.

Lee, N., \& Motzkau, J. (2013). Varieties of biosocial imagination: Reframing responses to climate change and antibiotic resistance. Science, Technology \& Human Values, 38(4) 447-469.

Lenz-Taguchi, H. (2010). Going Beyond the theory/practice divide in early childhood education: Introducing an intra-active pedagogy. London, UK: Routledge.

Lloro-Bidart, T. (2015). A political ecology of education in/for the Anthropocene. Environment and society, 6(1), 128.

Malone, K. (2015). Posthumanist approaches to theorising children's human-nature relations. In K. Nairn, P. Kraftl \& T. Skelton (Eds.), Space, place and environment (pp. 1-22). Singapore: Springer.

Malone, K. (2016). Reconsidering children's encounters with nature and place using posthumanism. Australian Journal of Environmental Education, 32(01), 42-56.

Manning, E. (2016). The Minor Gesture. Durham, NC: Duke University Press.

Massumi, B. (2002). Parables for the virtual: Movement, affect, sensation. Durham: Duke University Press.

Massumi, B. (2011). Semblance and Event: Activist philosophy and the occurrent arts. Cambridge, MA: Massachusetts Institute of Technology.

Morton, T. (2007). Ecology without nature: Rethinking environmental aesthetics. Cambridge, MA: Harvard University Press.

Payne, P., Cutter-Mackenzie, A., Gough, A., Gough, N., \& Whitehouse, H. (2014). Childrens' Conceptions of Nature. Australian Journal of Environmental Education, 30(1), 68.

Protevi, J. (2013). Life, war, earth: Deleuze and the sciences. Minneapolis: University of Minnesota Press.

Prout, A. (2005). The future of childhood: Towards the interdisciplinary study of children. New York: Routledge.

Rautio, P. (2014). Mingling and imitating in producing spaces for knowing and being: Insights from a Finnish study of child-matter intra-action. Childhood, 21(4), 461-474.

Robinson, K. (2009). Deleuze, Whitehead, Bergson: Rhizomatic connections. Rotterdam, NL: Springer.

Rousell, D., Cutter-Mackenzie, A., \& Foster, J. (2017). Children of an Earth to Come: Speculative fiction, geophilosophy, and climate change education research. Special Issue of Educational Studies on Alternative Approaches to STEM.

Rousell, D. \& Fell, F. (in press). Becoming a work of art: Collaboration, materiality and posthumanism in tertiary visual arts education. The International Journal of Education Through Art [Special Issue on Speculative Realisms and Materialisms]. 
Shaviro, S. (2009). Without criteria: Kant, Whitehead, Deleuze, and aesthetics. Cambridge, MA: MIT Press.

Shaviro, S. (2014). The universe of things: On speculative realism. Minneapolis: University of Minnesota Press.

Shaviro, S. (2015). Discognition. London, UK: Repeater Books.

Simondon, G. (1958). On the mode of existence of technical objects (N. Mellamphy, Trans.). Paris: Aubier.

Somerville, M. (2017). The Anthropocene's call to educational research. In K. Malone, S. Truong, \& T. Gray, Reimagining Sustainability in Precarious Times (pp. 17-28). Singapore: Springer.

Stables, A. (2001). Who drew the sky: Conflicting assumptions in environmental education. Educational Philosophy and Theory, 33(2), 245-257.

Steffen, W., Broadgate, W., Deutsch, L., Gaffney, O., \& Ludwig, C. (2015). The trajectory of the Anthropocene: The great acceleration. The Anthropocene Review, 2(1), 81-98.

Taylor, A. (2013). Reconfiguring the natures of childhood. Oxon, UK: Routledge.

Taylor, A., \& Pacini-Ketchabaw, V. (2015). Learning with children, ants, and worms in the Anthropocene: Towards a common world pedagogy of multispecies vulnerability. Pedagogy, Culture \& Society, 23(4), 507-529.

Whitehead, A. N. (1929a). The aims of education and other essays. New York, NY: Macmillan Company. Whitehead, A.N. (1967a). Adventures of ideas. New York: The Free Press.

Whitehead, A. N. (1967b). Science and the modern world. New York: The Free Press.

Whitehead, A.N. (1968). Modes of thought. New York: The Free Press.

Whitehead, A.N. (1978). Process and reality. New York: The Free Press.

Youdell, D. (2017). Bioscience and the sociology of education: the case for biosocial education. British Journal of Sociology of Education, 1-14. 